VIII Congresso Brasileiro de Informática na Educação (CBIE 2019)

Anais do XXV Workshop de Informática na Escola (WIE 2019)

\title{
Recursos Digitais na Aprendizagem de Espanhol pelo Público da Educação de Jovens e Adultos
}

\author{
Aladir Ferreira da Silva Júnior ${ }^{1}$, Rita Rodrigues de Souza ${ }^{2}$ \\ 1,2 Núcleo de Informática na Educação (NINE) - Instituto Federal de Goiás (IFG) \\ CEP. 75.804-714 - Jataí - GO - Brasil \\ \{aladir.junior ${ }^{1}$,rita.souza $\left.{ }^{2}\right\} @$ ifg.edu.br
}

\begin{abstract}
This article reports on an experience with the use of digital resources for learning the Spanish language by students of Youth and Adult Education (EJA). Through a mini-course, free technological resources for the learning of Spanish were made available, in blog format, to the public of the EJA. The resources were selected considering the possibility of autonomous learning of reading, grammar, lexical aspects, listening comprehension and conversation. After quali-quantitative analysis of the data collected through observation and questionnaire, we obtained the public's perception about how to learn Spanish using the digital resources, the interaction between participants and the appropriation of the technology present in the blog.
\end{abstract}

Resumo. Neste artigo, relatamos uma experiência de uso de recursos digitais para aprendizagem da língua espanhola na Educação de Jovens e Adultos (EJA). Por meio de uma oficina, foi disponibilizado ao público EJA, um blogue com recursos digitais gratuitos, selecionados considerando o aprendizado autônomo de leitura, aspectos gramaticais, léxicos, compreensão auditiva e conversação em língua espanhola. Após análise quali-quantitativa dos dados coletados por meio de observação e questionário, obtivemos a percepção desse público acerca da aprendizagem de espanhol com o uso de recursos digitais, de interação entre os participantes e apropriação da tecnologia presente no blogue.

\section{Introdução}

A temática da experiência/pesquisa agrega três pontos principais: o estudo de língua estrangeira, a EJA e tecnologias digitais na Educação. A junção desses três pontos, permitiunos refletir não somente acerca da especificidades de cada um, mas também como um pode ressignificar o outro. Em relação ao aprendizado de língua estrangeira, podemos elencar vários pontos positivos para o aprendiz: (i) ser um diferencial na carreira; (ii) ganhar em competências interculturais, possibilitando vínculos com pessoas de nacionalidades distintas; (iii) desenvolver habilidades multitarefas; e, (iv) fortalecer a capacidade cognitiva ao longo da vida (GALILEU, 2016).

A pesquisa prioriza o espanhol primeiro por estar presente nas escolas brasileiras estaduais, particulares e institutos federais (IF), com mais ênfase no ensino médio. Segundo, por sua importância no contexto mundial, sendo considerada a segunda língua mais falada no mundo com mais de 577 milhões de falantes (VÍTORES, 2018).

Cruz e Monteiro (2018, p. 90), no Anuário Brasileiro da Educação Básica, alertam que embora a EJA apresente "idealmente, um forte papel de combate à desigualdade produzida pelas deficiências do sistema educacional", essa modalidade continuará replicando alguns padrões de desigualdade, caso continue uma oferta desvinculada das necessidades do público-alvo. Isso ratifica a importância de pesquisas sobre essa modalidade. 
VIII Congresso Brasileiro de Informática na Educação (CBIE 2019)

Anais do XXV Workshop de Informática na Escola (WIE 2019)

A experiência compartilhada neste artigo discute a interação do público EJA com recursos digitais selecionados, tendo como base vídeos, textos, imagens e atividades para o desenvolvimento de habilidades de comunicação e interação, mais apropriadas para esse público, via TDIC, a partir de um blogue.

\section{As TDIC na EJA}

Esforços envolvendo o uso das TDIC, para aprendizagem do público da EJA, têm sido objeto de pesquisa. As TDIC são ferramentas que podem e devem ser trabalhadas para que o aluno exerça o protagonismo na construção de conhecimento. Bathke e Raabe (2016), por exemplo, obtiveram como resultados de pesquisa indícios de inclusão digital, empoderamento e pensamento computacional de estudantes da EJA.

Segundo Bathke e Raabe (2016, p.10), os alunos da EJA “já possuem uma história de vida, um trabalho, filhos, traumas, problemas, e esta situação também traz uma dificuldade em equalizar toda a turma", evidenciando a necessidade de se considerar a posse de saberes que esses alunos têm, bem como a escolha de recursos mais adequados ao seu perfil. Assim, sites que tratem de temas do mundo do trabalho, aspectos culturais de interesse do alunado da EJA, questões que fomentem discussão e reflexão foram considerados para compor o repertório disponibilizado no blogue.

É importante que o interesse do público da EJA seja sempre considerado pelo professor. Bathke e Raabe (2016, p.10) destacam que "é preciso ter a consciência de que os adultos estão na escola por vontade própria, ninguém os exige frequência, e caso não estejam gostando das aulas, ou tenham dificuldade em algumas das atividades, levantam e vão embora sem hesitar". Seguindo a linha de Bathke e Raabe (2016), Pereira e Ortiz (2017) realizaram pesquisa sobre o desenvolvimento do pensamento computacional no ensino de EJA. De acordo com os autores, a motivação foi de sensibilizar a academia para a importância de se investigar, propor e experimentar atividades, respeitando as particularidades do público da EJA.

Joaquim e Pesce (2016) realizaram revisão da literatura acadêmica sobre a utilização das TDIC na EJA no período de 2007 a 2014. Tiveram três constatações: (1) a escassez de trabalhos sobre a inserção das TDIC na EJA; (2) o consenso de autores sobre a importância das TDIC no aprendizado e (3) a importância de se refletir sobre a formação do professor para atuar com as TDIC na EJA. Isso reforça a importância da pesquisa relatada neste artigo.

Verificar como se daria o uso dos dispositivos móveis na EJA foi o objetivo de Santos e Sousa (2017). De acordo com as autoras, ainda há resistência por parte do professor em trabalhar o uso do celular em sala de aula, apesar de que, na sua maioria, os professores dominam essa tecnologia e a usam no cotidiano. O trabalho sugere a adesão à uma metodologia que abarque nativos digitais e imigrantes digitais da EJA.

Diferentemente do trabalho de Santos e Sousa (2017), não focamos nos diversos suportes a serem usados, mas sim na tecnologia organizacional que disponibiliza o conteúdo, nesse caso um blogue. É um fator que julgamos importante pois, independente do suporte (p. ex. computador de mesa, notebook, tablet ou smartphone) utilizado, o conteúdo poderá ser fornecido de forma organizada e estruturada.

O trabalho realizado, em relação aos já apresentados aqui, diferencia-se pela disponibilização de contato direto do público da EJA com as TDIC e não foca no desenvolvimento do pensamento computacional como os de Bathke e Raabe (2016) e em Pereira e Ortiz (2017). Prima pela apropriação das TDIC para aplicação direta no aprendizado. Esperamos que os resultados da presente pesquisa contribuam, em alguma medida, com esse cenário. 
VIII Congresso Brasileiro de Informática na Educação (CBIE 2019)

Anais do XXV Workshop de Informática na Escola (WIE 2019)

\section{Métodos e Procedimentos}

Relatamos, aqui, uma pesquisa quali-quantitativa que mapeou links (sites de jornais, vídeos e atividades) que proporcionam acesso gratuito a conteúdos que favorecem a aprendizagem do espanhol, mais apropriados para o público da EJA. O material foi disponibilizado em um blogue, recurso que, segundo Blood (2013), tem sido remodelado e, atualmente, é usado com os mais diversos fins, incluindo os educacionais.

Utilizamos, para aplicação da pesquisa, uma oficina especificamente para a EJA, realizada na XIV Semana de Computação - SECOMP, do Instituto Federal de Goiás, Câmpus Jataí. Tivemos a participação de 37 alunos do curso Técnico Integrado em Secretariado, na modalidade EJA, organizados aleatoriamente em dois laboratórios com 30 computadores cada, assim o participante acessou a máquina individualmente.

A oficina foi dividida em quatro momentos. Durante o momento de (i) sensibilização, apresentamos, por meio de um arquivo de apresentação eletrônica, curiosidades referentes à quantidade de falantes de espanhol no mundo e dados científicos sobre as vantagens de se aprender uma língua estrangeira. No momento seguinte (ii), explicamos a pesquisa que deu origem à oficina. Tratamos a metodologia, os critérios para seleção do material disponibilizado para o público da EJA e o blogue intitulado Escola Espanhol ${ }^{1}$, de autoria dos pesquisadores. Ressaltamos que tais recursos foram selecionados com base na gratuidade, possibilidade de aprendizado autônomo de leitura, de aspectos gramaticais, lexicais, de compreensão auditiva e de conversação.

No terceiro momento (iii), os discentes tiveram acesso ao blogue e puderam navegar nas seções (sites, vídeos, atividades e jornais). Durante essa etapa, também esclarecemos aos participantes que eles podiam curtir aquele recurso considerado satisfatório e/ou interessante, sinalizando isso por meio da ferramenta curtir do próprio blogue. Era possível, também, comentar cada postagem, desde que o usuário se autenticasse, seja pelo cadastro no blogue, ou ainda pelo Facebook ou conta Google.

$\mathrm{Na}$ etapa de (iv) avaliação, foi solicitado aos participantes que respondessem a um questionário online acerca das percepções sobre a condução da oficina, bem como do contato com a tecnologia de blogue e da internet, para a aprendizagem da língua espanhola. Do total de 37 participantes, obtivemos 32 respostas ao questionário, com as respectivas autorizações para uso e divulgação de dados, apresentados a seguir.

\section{Resultados e Discussão}

Em relação à faixa etária, tivemos que 25,0\% (8) dos respondentes têm entre 18 e 21 anos, $65,6 \%$ (21) têm entre 22 e 40 anos, e ainda com 9,4\% (3) com idades variando entre 41 a 60 anos. Percebemos que a maior parte do público tem acima de 21 anos que se somados à faixa superior, totaliza 75\% (24). Quanto ao sexo, o público é formado majoritariamente por mulheres $(71,9 \%$ - 23) contra $28,1 \%$ de homens (9).

A partir desses resultados é esperado que nem todos tivessem domínio das TDIC, em especial do uso da internet e blogues, pois parte desse público não pode ser considerada como nativos digitais (nascidos a partir de 1980) e sim como imigrantes digitais (PRENSKY, 2001). No entanto, percebemos, pela observação em laboratório, que, apesar de algum transtorno inicial em relação ao esquecimento de senhas de $e$-mails, o público não apresentou dificuldades no acesso dos recursos do blogue.

1Acesso via endereço: http://gg.gg/escolaespanhol 
VIII Congresso Brasileiro de Informática na Educação (CBIE 2019)

Anais do XXV Workshop de Informática na Escola (WIE 2019)

Em relação à aprendizagem de língua estrangeira, 96,9\% (31) consideram essencial. Apenas 3,1\%, uma pessoa, respondeu que não vê essa necessidade, pois ela não sairá do país. Percebemos que a maioria dos respondentes, mesmo com a probabilidade de não sair fisicamente do país, verifica a importância da aprendizagem de uma língua além da materna, seja para se comunicar por meio das inúmeras tecnologias disponíveis atualmente, seja para estudo de materiais escritos em outro idioma, dentre outras possibilidades.

Quanto à tecnologia de blogue, por unanimidade (100\%) foi considerada válida para o aprendizado de uma língua estrangeira. Quanto ao tipo de conteúdo apresentado nas postagens (vídeos, sites, jornais), obtivemos que 68,8\% (22) consideram essencial e que poderiam estudar sozinhos usando essas tecnologias. Adicionalmente, 31,2\% (10) acham importante, como opção de reforço da aprendizagem. As opções: "Vejo pouca importância e prefiro aprender em escolas de idiomas" e "Não vejo importância nenhuma" não foram escolhidas por nenhum dos respondentes. Isso pode ser um indício de que o(a) respondente não via necessidade da aprendizagem de um outro idioma, possa não ter feito uma opção conclusiva acerca dessa consideração, pois caso contrário teria marcado uma dessas opções.

Acerca da navegação no blogue Escola Espanhol, 87,5\% (28) afirmaram não ter tido dificuldade alguma durante a navegação e, adicionalmente, $12,5 \%$ (4) disseram ter navegado em todo o blogue, porém com alguma dificuldade. Ninguém respondeu "Naveguei, porém achei confuso" ou ainda "Não consegui navegar", o que pode indicar que o blogue apresenta uma boa navegabilidade, uma fluidez na apresentação dos conteúdos (postagens) que facilitam a navegação.

Quanto ao conteúdo do blogue Escola Espanhol, 90,6\% (29) acham o conteúdo rico e 9,4\% (3) acham o conteúdo bom, com possibilidades de melhoria. Aqui ressalta-se que o blogue pode ser atualizado com a frequência desejada, pois ele possui uma estrutura que permite a postagem a qualquer momento pelo administrador, seja um professor ou outra pessoa designada.

O questionário apresentou, também, um espaço para sugestões, críticas ou qualquer comentário do(a) participante acerca de melhorias para o blogue. Tivemos algumas observações acerca de lentidão no acesso. O participante P1: "O site está um pouco lento, mas com um pouco de paciência atende todas a necessidades sobre o curso!!!", que também foi corroborada pelos participantes P14 e P15 que responderam respectivamente "alguns sites estão lentos" e "Os sites estão muito lentos. Tirando esse detalhe, tudo perfeito." Essas observações podem ser atribuídas ao fato de que durante o momento prático da oficina, muitos assistiram a vídeos, o que consome mais dados e pode causar lentidão aos demais, haja vista que o link de internet da instituição é compartilhado com mais de dez laboratórios.

Os participantes P2, P14, P25 e P30 apontaram para a necessidade de outros tipos de recursos além dos apresentados no blogue Escola Espanhol. Para P2, uma alternativa seria o "ensino por meio de músicas em espanhol.". De acordo com P14 e P25, respectivamente, há a necessidade de se "colocar mais jogos" e ter "mais joguinho, brincadeira para aprender brincando." Para P30, é preciso "ter mais coisas atraentes". Essas considerações impulsionam para a criação de novas categorias de recursos, além da busca por novos que contenham, por exemplo, jogos ou músicas para aprendizagem do espanhol, facilmente suportados pela ferramenta blogue.

Ainda como sugestões, alguns participantes afirmaram que deveriam existir mais momentos como o da oficina. P6 afirmou que: "precisa ter mais vezes os minicursos", P9: "poderia ter mais minicurso". Essas afirmações remetem à necessidade do professor proporcionar momentos diferentes da aula ministrada em um formato tradicional. 
VIII Congresso Brasileiro de Informática na Educação (CBIE 2019)

Anais do XXV Workshop de Informática na Escola (WIE 2019)

\section{Conclusão}

O blogue pode facilitar o engajamento dos alunos com a proposta de aprendizagem sugerida pelo professor. A estrutura dele não traz sobressaltos àqueles já acostumados ao acesso e uso das redes sociais, em que se tem recursos de curtir, compartilhar, comentar a postagem ou, até mesmo, comentar acerca de um outro comentário. Para aqueles não familiarizados com redes sociais, o blogue pode iniciá-los nesse processo. O blogue tem menos recursos que essas redes, possibilitando um entendimento gradual das funcionalidades disponíveis nessas.

Verificamos que, apesar de que o público da EJA, seja parcialmente representado por imigrantes digitais, foi receptivo às TDC, especialmente blogue e internet. Também ficou evidente o interesse desse público em aprender uma língua estrangeira, por meio desses recursos tecnológicos e ainda de forma autônoma. Isso é importante porque trata-se de um público predominantemente trabalhador e que pode ter seu conhecimento fortalecido por meio de tecnologias que ampliam o espaço da sala de aula e que permitem acessar conteúdos mais apropriados ao seu perfil.

Apesar da autonomia pretendida pelo professor, há de se considerar que, inicialmente e especialmente, para a EJA, é necessário se apontar caminhos para o desenvolvimento dos trabalhos. Um das formas poderia ser o fornecimento de links, seja por meio de blogues, como foi feito nesta pesquisa, ou por meio de uma WebQuest ou ainda de um recurso de repositório de links.

\section{Referências}

BATHKE, J.; RAABE, A. Pensamento Computacional na Educação de Jovens e Adultos: Lições Aprendidas. Anais dos Workshops do Congresso Brasileiro de Informática na Educação, v. 5, n. 1, p. 1087, 2016.

BLOOD, R. Weblogs: A History and Perspective - Rebecca's Pocket. Criado em: 07 September 2000. Atualizado em: 18 September 2013. Disponível em: http://www.rebeccablood.net/essays/weblog_history.html. Acesso em jul. 2019.

CRUZ, P.; MONTEIRO, L. Anuário Brasileiro da Educação Básica. São Paulo: Moderna, 2018.

GALILEU. 5 razões científicas para aprender outro idioma: Estudos comprovam os benefícios cognitivos de quem é bilíngue. Editora Globo: São Paulo, dez. 2016.

JOAQUIM, B. dos S.; PESCE, L. As Tecnologias Digitais da Informação e da Comunicação nos contextos da Educação de Jovens e Adultos: Uma Revisão De Literatura (2007-2014). Olh@ res: Revista do Departamento de Educação da Unifesp, v. 4, n. 1, p. 86-106, 2016.

PRENSKY, M. Digital Native, Digital Immigrants. On the horizon, MCB University Press, Vol. 9, N.5, October, 2001. Disponível em: http://gg.gg/prensky. Acesso em: jul. 2019.

ORTIZ, J.; PEREIRA, R. Pensamento Computacional na Educação de Jovens e Adultos: desafios e oportunidades. Anais dos Workshops do VI Congresso Brasileiro de Informática na Educação (CBIE 2017), v. 1, n. 1, p. 1069, 2017.

SANTOS, T.; SOUSA, P. O Uso dos Dispositivos Móveis na Educação de Jovens e Adultos. Trabalho de Conclusão de Curso. Faculdade de Pedagogia. Universidade Federal da Paraíba (UFPB), 2017.

VÍTORES, D. F. El Español: Una Lengua Viva - Informe 2018. Departamento de Comunicación Digital del Instituto Cervantes: Madrid. 72p., 2018. 